\title{
COVID-19: risk factors for severe cases of the Delta variant
}

\author{
Kaiyuan Hu${ }^{1}$, Liu Lin ${ }^{1}$, Ying Liang ${ }^{1}$, Xinning Shao ${ }^{1}$, Zhongwei Hu${ }^{1}$, Hongbin Luo ${ }^{1}$, Ming Lei ${ }^{1}$ \\ ${ }^{1}$ Guangzhou Eighth People's Hospital, Guangzhou Medical University, Guangzhou, China
}

Correspondence to: Ming Lei; email: gz8hlmsn@126.com, https://orcid.org/0000-0003-3442-7099

Keywords: COVID-19, Delta variant, severe cases, clinical features, risk factors

Received: June 28, $2021 \quad$ Accepted: October 3, $2021 \quad$ Published: October 28, 2021

Copyright: (C) $2021 \mathrm{Hu}$ et al. This is an open access article distributed under the terms of the Creative Commons Attribution License (CC BY 3.0), which permits unrestricted use, distribution, and reproduction in any medium, provided the original author and source are credited.

\begin{abstract}
Background: Since April 2021, the SARS-CoV-2 (B.1.167) Delta variant has been rampant worldwide. Recently, this variant has spread in Guangzhou, China. Our objective was to characterize the clinical features and risk factors of severe cases of the Delta variant in Guangzhou.

Methods: A total of 144 patients with the Delta variant were enrolled, and the data between the severe and non-severe groups were compared. Logistic regression methods and Cox multivariate regression analysis were used to investigate the risk factors of severe cases.

Results: The severity of the Delta variant was $11.1 \%$. Each 1 -year increase in age (OR, 1.089; $95 \% \mathrm{Cl}, 1.035-$ 1.147; $P=0.001)$ and each $1-\mu \mathrm{mol} / \mathrm{L}$ increase in total bilirubin $(\mathrm{OR}, 1.198 ; 95 \% \mathrm{Cl}, 1.021-1.406 ; P=0.039)$ were risk factors for severe cases. Moreover, the risk of progression to severe cases increased 13.444-fold and 3.922fold when the age was greater than 58.5 years (HR, 13.444; 95\% Cl, 2.989-60.480; $P=0.001$ ) or the total bilirubin level was greater than $7.23 \mu \mathrm{mol} / \mathrm{L}(\mathrm{HR}, 3.922 ; 95 \% \mathrm{Cl}, 1.260-12.207 ; P=0.018)$, respectively.

Conclusion: Older age and elevated total bilirubin were independent risk factors for severe cases of the Delta variant in Guangzhou, especially if the age was greater than $\mathbf{5 8 . 5}$ years or the total bilirubin level was greater than $7.23 \mu \mathrm{mol} / \mathrm{L}$.
\end{abstract}

\section{INTRODUCTION}

Up to June 24, 2021, more than 180 million cases have been diagnosed in more than 200 countries, with a mortality rate of about $2.17 \%$ [1]. Although many countries have started vaccinating, the virus mutates and new variants have been appearing, such as the Alpha variant in the UK and the Delta variant in India. Since the Delta variant was first identified in October 2020 in India, it has spread widely worldwide and is now the major epidemic strain [2,3]. Due to strict control, no local COVID-19 cases have been found in Guangzhou, China, for more than one year. However, a new local case appeared in Guangzhou on May 21, 2021, and the number of diagnosis cases had exceeded 100 by June 14 , 2021. Genetic analysis confirmed that the Delta variant strain caused this outbreak. This is the first indigenous COVID-19 outbreak in China caused by the Delta variant. The goal of this study was to investigate the clinical features and risk factors for severe cases with the Delta variant in Guangzhou. Monitoring these factors can help clinicians identify severe cases early and take subsequent interventions to control and reduce the illness.

\section{RESULTS}

Baseline characteristics

Among the 144 patients, $16(11.1 \%)$ were in the severe group, and no patient died by the end of the study. The median age of all patients was 48.5 years (IQR 30.363.8 ), and $59.7 \%$ of the patients were female (Table 1). The most common comorbidity was hypertension (24, $16.7 \%)$, followed by diabetes $(8,5.6 \%)$ and cardiovascular disease (CVD; 5, 3.5\%; Table 1). Twenty-six patients (18.1\%) received one or two doses of the COVID-19 vaccine (Table 1). Cough (70, 48.6\%) was the most common symptoms on admission, 
Table 1. Baseline characteristics of non-severe or severe patients of Delta variant in Guangzhou.

\begin{tabular}{|c|c|c|c|c|}
\hline \multirow{2}{*}{ Demographics and clinical characteristics } & \multicolumn{3}{|c|}{ No. $(\%)$} & \multirow{2}{*}{$P$ value } \\
\hline & Total (144) & Non-severe (128) & Severe (16) & \\
\hline Age, median (IQR), years & $47.5(30.3-63.8)$ & $45(25-59.5)$ & $72(63-83)$ & $<0.001$ \\
\hline Age groups (years): & .. & .. & .. & $<0.001$ \\
\hline$\leq 58.5$ & $98(68.1)$ & $96(75)$ & $2(12.5)$ & .. \\
\hline$>58.5$ & $46(31.9)$ & $32(25)$ & $14(87.5)$ & \\
\hline Sex: & .. & .. & .. & 1.000 \\
\hline Male & $58(40.3)$ & $52(40.6)$ & $6(37.5)$ & .. \\
\hline Female & $86(59.7)$ & $76(59.4)$ & $10(62.5)$ & .. \\
\hline Comorbidity: & .. & .. & .. & .. \\
\hline Hypertension & $24(16.7)$ & $17(13.3)$ & $7(43.8)$ & 0.006 \\
\hline Diabetes & $8(5.6)$ & $6(4.7)$ & $2(12.5)$ & 0.479 \\
\hline CVD & $5(3.5)$ & $4(3.1)$ & $1(6.3)$ & 1.000 \\
\hline Fever: & .. & .. & .. & 0.066 \\
\hline $\mathrm{T}<37.3^{\circ} \mathrm{C}$ & $86(59.7)$ & $77(60.2)$ & $9(56.3)$ & .. \\
\hline $37.3^{\circ} \mathrm{C} \leq \mathrm{T}<38.1^{\circ} \mathrm{C}$ & $26(18.1)$ & $24(18.8)$ & $2(12.5)$ & .. \\
\hline $38.1^{\circ} \mathrm{C} \leq \mathrm{T}<39^{\circ} \mathrm{C}$ & $26(18.1)$ & $24(18.8)$ & $2(12.5)$ & .. \\
\hline $39^{\circ} \mathrm{C} \leq \mathrm{T}$ & $6(4.2)$ & $3(2.3)$ & $3(18.8)$ &.. \\
\hline Cough & $70(48.6)$ & $62(48.4)$ & $8(50)$ & 0.906 \\
\hline Sputum & $45(31.3)$ & $39(30.5)$ & $6(37.5)$ & 0.567 \\
\hline Fatigue & $16(11.1)$ & $13(10.2)$ & $3(18.8)$ & 0.542 \\
\hline Nausea and Vomiting & $2(1.4)$ & $2(1.6)$ & $0(0)$ & 1.000 \\
\hline Diarrhea & $5(3.5)$ & $4(3.1)$ & $1(6.3)$ & 1.000 \\
\hline Headache & $17(11.8)$ & $16(12.5)$ & $1(6.3)$ & 0.749 \\
\hline Sore throat & $24(16.7)$ & $19(14.8)$ & $5(31.3)$ & 0.192 \\
\hline Vaccination & $26(18.1)$ & $26(20.3)$ & $0(0)$ & 0.100 \\
\hline Survival time & $11(6-14)$ & $12(8-14)$ & $4(4-5.8)$ & $<0.001$ \\
\hline
\end{tabular}

Abbreviations: CVD: Cardiovascular disease; T: Temperature. $P$ values indicate differences between Severe and Non-severe patients. $P<0.05$ was considered statistically significant.

followed by fever $(58,40.3 \%)$, sputum $(45,31.3 \%)$, sore throat $(24,16.7 \%)$, headache $(17,11.8 \%)$, fatigue $(16,11.1 \%)$, and diarrhea $(5,3.5 \%$; Table 1$)$.

\section{Laboratory and radiological findings}

Compared with non-severe patients, lymphocytes, platelets, and albumin were significantly reduced, whereas creatinine, C-reactive protein (CRP), total bilirubin, D-dimer, procalcitonin (PCT), and blood glucose were significantly increased in patients in the severe group (Table 2). Furthermore, the levels of nucleocapsid protein and open reading frame $1 \mathrm{ab}$ (ORF1ab) in the non-severe group were higher than in the severe group, indicating that the viral load was higher in the latter (Table 2). Thirty-one (21.5\%) patients had unilateral pneumonia, and only two of them were severe cases; $64(44.4 \%)$ patients had bilateral pneumonia, and $13(81.3 \%)$ of these were severe cases (Table 2). 
Table 2. Laboratory and radiological findings of non-severe or severe patients of Delta variant in Guangzhou.

\begin{tabular}{|c|c|c|c|c|c|}
\hline & \multicolumn{3}{|c|}{ Median (IQR) } & \multirow{2}{*}{$P$ value } & \multirow{2}{*}{$\begin{array}{c}\text { Normal } \\
\text { range }\end{array}$} \\
\hline & Total (144) & Non-severe (128) & Severe (16) & & \\
\hline Laboratory findings: & .. & .. & .. & .. & .. \\
\hline WBC $(\times 109 / \mathrm{L})$ & $5.8(4.6-6.9)$ & 5. 8(4.7-7.0) & $5.1(4.2-6.3)$ & 0.232 & $4-10$ \\
\hline Lymphocyte count $(\times 109 / \mathrm{L})$ & $1.1(0.8-1.5)$ & $1.1(0.8-1.6)$ & $1.0(0.7-1.1)$ & 0.013 & $1.1-3.2$ \\
\hline Hemoglobin $(\mathrm{g} / \mathrm{L})$ & $133(125-145)$ & $134(126-145)$ & $131(123-147)$ & 0.602 & $130-175$ \\
\hline Platelet count $(\times 109 / \mathrm{L})$ & $192(156-241)$ & $198(160-245)$ & $159(135-195)$ & 0.013 & $125-350$ \\
\hline $\mathrm{CRP}(\mathrm{mg} / \mathrm{L})(\mathrm{No}(\%))$ : & .. & .. & .. & .. & $\leq 10$ \\
\hline$>10$ & $46(31.9)$ & $34(26.6)$ & $12(75)$ & $<0.001$ & .. \\
\hline PCT $(n g / m L)$ & $0.06(0.04-0.09)$ & $0.06(0.04-0.08)$ & $0.10(0.06-0.13)$ & 0.015 & $<0.05$ \\
\hline D-dimer (mg/L FEU) & $0.31(0.18-0.44)$ & $0.28(0.17-0.43)$ & $0.44(0.35-0.58)$ & 0.001 & $<0.55$ \\
\hline $\operatorname{ALT}(\mathrm{U} / \mathrm{L})$ & $14.3(9.9-19.7)$ & $14.0(9.9-18.9)$ & $15.1(12.7-25.0)$ & 0.416 & $9-50$ \\
\hline $\operatorname{AST}(\mathrm{U} / \mathrm{L})$ & $20.1(15.8-27.1)$ & $19.6(15.8-26.0)$ & $20.8(18.9-29.9)$ & 0.352 & $15-40$ \\
\hline Total bilirubin $(\mu \mathrm{mol} / \mathrm{L})$ & $6.5(4.7-8.7)$ & $6.5(4.5-8.3)$ & $8.2(6.7-12.4)$ & 0.009 & $3.4-17.1$ \\
\hline Total bilirubin $(\mu \mathrm{mol} / \mathrm{L})(\mathrm{No}(\%))$ : & .. & .. & .. & 0.002 & .. \\
\hline$>7.23$ & $56(38.9)$ & $44(34.4)$ & $12(75)$ & .. & .. \\
\hline$\leq 7.23$ & $88(61.1)$ & $84(65.6)$ & $4(25)$ & .. & .. \\
\hline $\operatorname{Albumin}(\mathrm{g} / \mathrm{L})$ & $43.4(39.9-46.3)$ & $44.4(40.6-46.6)$ & $39.8(36.5-42.0)$ & 0.001 & $40-55$ \\
\hline Creatinine $(\mu \mathrm{mol} / \mathrm{L})$ & $67.3(55.0-78.9)$ & $65.6(54.0-76.1)$ & $76.0(68.1-93.9)$ & 0.021 & $54-106$ \\
\hline Creatinine kinase (U/L) & $104(76-149)$ & $100(77-148)$ & $110(72-232)$ & 0.473 & $50-310$ \\
\hline Uric Acid $(\mu \mathrm{mol} / \mathrm{L})$ & $307(245-371)$ & $308(250-371)$ & $291(204-411)$ & 0.629 & $180-420$ \\
\hline Blood glucose $(\mathrm{mmol} / \mathrm{L})$ & $6.1(5.2-7.3)$ & $6.0(5.2-7.0)$ & $8.5(6.6-9.9)$ & 0.001 & $3.9-6.1$ \\
\hline Lactic acid $(\mathrm{mmol} / \mathrm{L})$ & $1.4(1.2-2.1)$ & $1.4(1.2-2.1)$ & $1.3(1.0-1.8)$ & 0.324 & $0.5-1.7$ \\
\hline Potassium $(\mathrm{mmol} / \mathrm{L})$ & $3.5(3.3-3.6)$ & $3.5(3.3-3.7)$ & $3.3(3.2-3.5)$ & 0.065 & $3.5-5.5$ \\
\hline RT-PCR: & .. & .. & .. & .. & .. \\
\hline Nucleocapsid protein & $23.2(19.5-28.4)$ & $23.6(19.8-28.4)$ & $20.2(18.5-29.1)$ & 0.320 & $>40$ \\
\hline ORF1ab & $25.0(20.7-30.0)$ & $25.5(21.0-30.0)$ & $22.3(19.5-29.6)$ & 0.342 & $>40$ \\
\hline Chest radiography findings: & .. & .. & .. & 0.005 & .. \\
\hline Unilateral pneumonia & $31(21.5)$ & $29(22.7)$ & $2(12.5)$ & .. & .. \\
\hline Bilateral pneumonia & $64(44.4)$ & $51(39.8)$ & $13(81.3)$ & .. & .. \\
\hline
\end{tabular}

Abbreviations: WBC: White blood cell; ALT: Alanine transaminase; AST: Aspartate aminotransferase; CRP: C-reactive protein; PCT: Procalcitonin; ORF1ab: open reading frame 1ab. $P$ values indicate differences between Severe and Non-severe patients. $P<0.05$ was considered statistically significant.

\section{Treatments and outcomes}

Only 14 patients received antibiotics, including three non-severe patients and 11 severe patients. There was a significant difference between the two groups. Eleven patients received glucocorticoid, and 16 patients received gamma globulin. Of the non-severe patients, 41 patients did not receive oxygen, and 47 patients only received normal-flux oxygen, while all severe patients received high-flow oxygen. All severe patients received 
high flows through nasal cannulae therapy. With the exacerbation of the disease, seven severe patients received tracheal intubation. Furthermore, one of them was treated with a tracheotomy and extracorporeal membrane oxygenation (ECMO). As of June 14, 13 severe patients were admitted to the intensive care unit (ICU), compared with only three non-severe patients (Table 3).

\section{Univariate and multivariate analysis of risk factors of severe cases}

Univariate logistic regression analysis found that age, hypertension, fever $\left(39^{\circ} \mathrm{C} \leq \mathrm{T}\right)$, total bilirubin, CRP, lymphocytes, blood glucose, and bilateral pneumonia were related to severe cases (Table 4). All variables with significant statistical differences in the univariate logistic regression analysis were used to construct a multivariable logistic regression model. The results suggested that each 1 -year increase in age (OR, 1.089; 95\% CI, 1.035-1.147; $P=0.001)$, each $1-\mu \mathrm{mol} / \mathrm{L}$ increase in total bilirubin $(\mathrm{OR}$, 1.198; 95\% CI, 1.021-1.406; $P=0.039)$, and temperature equal to or greater than $39^{\circ} \mathrm{C}(\mathrm{OR}, 25.292 ; 95 \% \mathrm{CI}$, 2.086-306.677; $P=0.011)$ were independent risk factors for severe cases (Table 4).

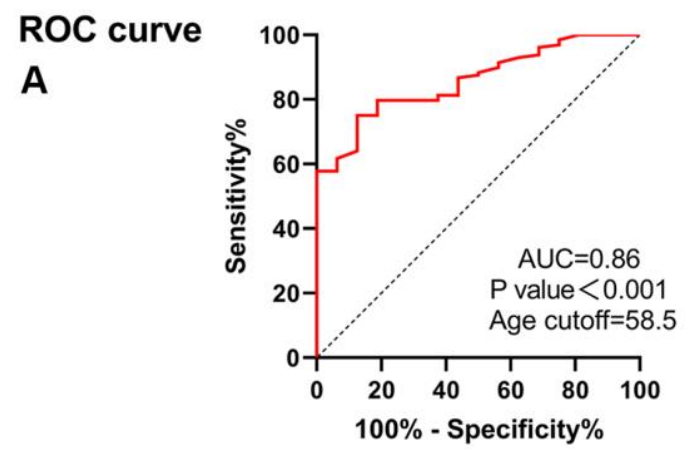

\section{Kaplan-Meier and multivariate COX analysis of risk factors of severe cases}

In the receiver operating characteristic (ROC) curve, the optimal cut-off value of age was 58.5 years, and the area under the curve (AUC) was 0.86 (Figure 1A). The optimal cut-off value of total bilirubin was $7.23 \mu \mathrm{mol} / \mathrm{L}$, and the AUC was 0.70 (Figure 1B). Therefore, KaplanMeier analysis suggested that age greater than 58.5 years, total bilirubin greater than $7.23 \mu \mathrm{mol} / \mathrm{L}$, and temperature equal to or greater than $39^{\circ} \mathrm{C}$ were risk factors for severe cases (Figure $1 \mathrm{C}-1 \mathrm{E}$ ). Multivariate cox analysis was performed on the above three factors. The results suggested that age greater than 58.5 years (HR, 13.444; 95\% CI, 2.989-60.480; $P=0.001$ ) and total bilirubin greater than $7.23 \mu \mathrm{mol} / \mathrm{L}$ (HR, 3.922; 95\% CI, 1.260-12.207; $P=0.018$ ) were independent risk factors for severe cases (Table 5).

\section{DISCUSSION}

In late 2019, SARS-CoV-2 broke out in Wuhan, with a severity rate as high as $31.7 \%$ in the early days [4] and eventually caused thousands of deaths in the city. The outbreak quickly spread to Guangzhou, where about

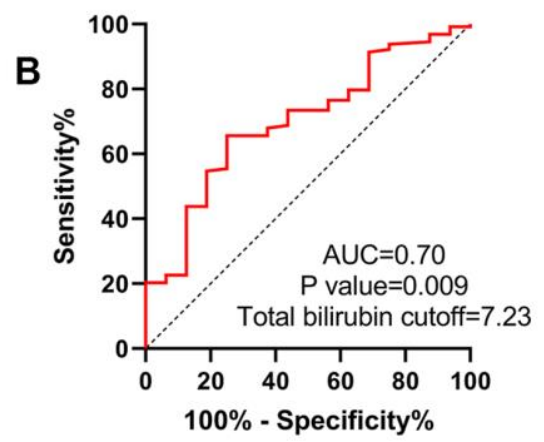

\section{Kaplan Meier}

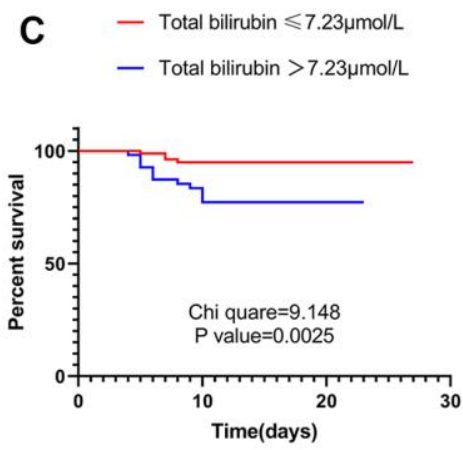

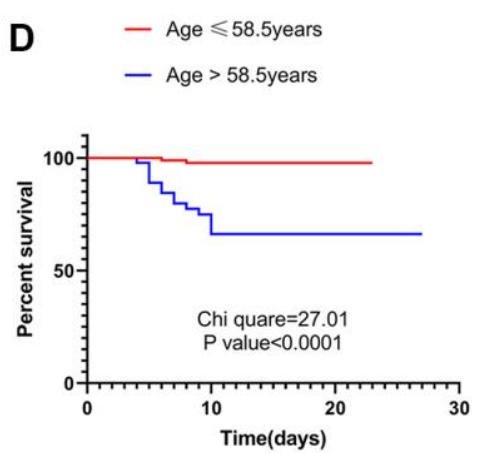

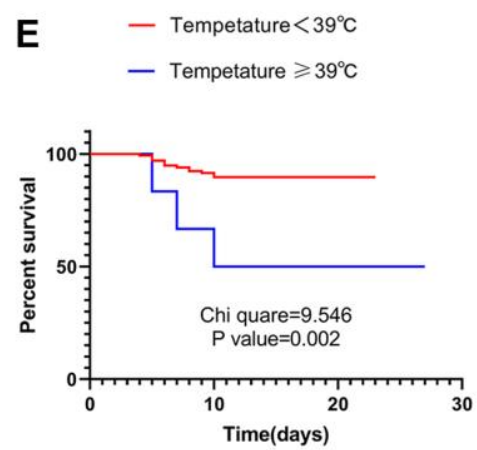

Figure 1. ROC curve and Kaplan Meier. (A) ROC curve suggested that age was valuable in predicting severe disease, and the cut-off point was 58.5 years. (B) ROC curve suggested that total bilirubin level was valuable in predicting severe disease, and the cut-off point was $7.23 \mu \mathrm{mol} / \mathrm{L}$. (C) Kaplan Meier analysis suggested that patients with total bilirubin levels greater than $7.23 \mu \mathrm{mol} / \mathrm{L}$ were more likely to develop into severe cases. (D) Kaplan Meier analysis suggested that patients with age greater than 58.5 years were more likely to develop into severe cases. (E) Kaplan Meier analysis suggested that patients with Temperature $\geq 39^{\circ} \mathrm{C}$ were more likely to develop into severe cases. Abbreviation: AUC: area under the curve. 
Table 3. Treatments and outcomes of non-severe or severe patients of Delta variant in Guangzhou.

\begin{tabular}{|c|c|c|c|c|}
\hline & \multicolumn{3}{|c|}{ No. $(\%)$} & \multirow{2}{*}{$P$ value } \\
\hline & Total (144) & Non-severe (128) & Severe (16) & \\
\hline \multicolumn{5}{|l|}{ Treatments: } \\
\hline Antibiotics & $14(9.7)$ & $3(2.3)$ & $11(68.8)$ & $<0.001$ \\
\hline Glucocorticoid & $11(7.6)$ & $4(3.1)$ & $7(43.8)$ & $<0.001$ \\
\hline Gamma globulin & $16(11.1)$ & $9(7)$ & $7(43.8)$ & $<0.001$ \\
\hline \multicolumn{5}{|l|}{ Oxygen uptake: } \\
\hline None & $41(28.5)$ & $41(32)$ & $0(0)$ & 0.017 \\
\hline Normal-flux & $47(32.6)$ & $47(36.7)$ & $0(0)$ & 0.003 \\
\hline High-flux & $55(38.9)$ & $40(31.3)$ & $16(100)$ & $<0.001$ \\
\hline High flows through nasal cannulae & $52(36.1)$ & $36(28.1)$ & $16(100)$ & $<0.001$ \\
\hline Tracheal intubation & $7(4.9)$ & $0(0)$ & $7(43.8)$ & $<0.001$ \\
\hline Tracheotomy & $1(0.7)$ & $0(0)$ & $1(6.3)$ & 0.111 \\
\hline ECMO & $1(0.7)$ & $0(0)$ & $1(6.3)$ & 0.111 \\
\hline \multicolumn{5}{|l|}{ Outcomes: } \\
\hline ICU Admission & $17(11.8)$ & $4(3.1)$ & $13(81.3)$ & $<0.001$ \\
\hline
\end{tabular}

Abbreviations: ECMO: Extracorporeal membrane oxygenation; ICU: intensive care unit. $P$ values indicate differences between Severe and Non-severe patients. $P<0.05$ was considered statistically significant.

Table 4. Univariate and multivariate analysis of risk factors of severe cases in Guangzhou.

\begin{tabular}{|c|c|c|c|c|}
\hline & Univariable OR (95\% CI) & $P$ value & Multivariable OR (95\%) CI) & $P$ value \\
\hline \multicolumn{5}{|c|}{ Demographics and clinical characteristics } \\
\hline Age, years & $1.089(1.043-1.137)$ & $<0.001$ & $1.089(1.035-1.147)$ & 0.001 \\
\hline \multicolumn{5}{|c|}{ Comorbidity present (vs not present) } \\
\hline Hypertension & $5.078(1.671-15.438)$ & 0.004 & .. & 0.755 \\
\hline Fever: & .. & 0.071 & .. & 0.091 \\
\hline $\mathrm{T}<37.3^{\circ} \mathrm{C}$ & 1 (ref) & .. & .. & \\
\hline $37.3^{\circ} \mathrm{C} \leq \mathrm{T}<38.1^{\circ} \mathrm{C}$ & $0.713(0.144-3.529)$ & 0.678 & .. & 0.783 \\
\hline $38.1^{\circ} \mathrm{C} \leq \mathrm{T}<39^{\circ} \mathrm{C}$ & $0.713(0.144-3.529)$ & 0.678 & .. & 0.721 \\
\hline $39^{\circ} \mathrm{C} \leq \mathrm{T}$ & $8.556(1.497-48.885)$ & 0.016 & $25.292(2.086-306.677)$ & 0.011 \\
\hline \multicolumn{5}{|c|}{ Laboratory and radiography findings } \\
\hline Lymphocyte count $(\times 109 / \mathrm{L})$ & $0.223(0.059-0.846)$ & 0.027 & .. & 0.076 \\
\hline Platelet count $(\times 109 / \mathrm{L})$ & $0.987(0.975-0.998)$ & 0.019 & .. & 0.256 \\
\hline $\mathrm{CRP}(\mathrm{mg} / \mathrm{L})(\mathrm{No}(\%))$ : & .. & .. & .. & .. \\
\hline$>10$ & $8.294(2.504-27.472)$ & 0.001 & .. & 0.230 \\
\hline PCT (ng/mL) & $2.748(0.147-51.428)$ & 0.499 & .. & .. \\
\hline
\end{tabular}




$\begin{array}{lcccc}\text { D-dimer }(\mathrm{mg} / \mathrm{L} \mathrm{FEU}) & 2.585(0.789-8.471) & 0.117 & . . & . . \\ \text { Total bilirubin }(\mu \mathrm{mol} / \mathrm{L}) & 1.168(1.029-1.326) & 0.016 & 1.198(1.021-1.406) & 0.039 \\ \text { Albumin }(\mathrm{g} / \mathrm{L}) & 0.971(0.934-1.009) & 0.131 & . . & . . \\ \text { Creatinine }(\mu \mathrm{mol} / \mathrm{L}) & 1.0(0.996-1.003) & 0.926 & . . & . . \\ \text { Blood glucose }(\mathrm{mmol} / \mathrm{L}) & 1.367(1.125-1.662) & 0.002 & . . & 0.444 \\ \text { Potassium (mmol/L) } & 0.319(0.076-1.342) & 0.119 & . . & . . \\ \text { CT feature (vs no pneumonia) } & . . & 0.023 & . . & 0.514 \\ \text { Unilateral pneumonia } & 3.31(0.287-38.144) & 0.337 & . . & 0.255 \\ \text { Bilateral pneumonia } & 12.235(1.541-97.136) & 0.018 & . . & 0.317\end{array}$

Abbreviations: OR: odds ratio; T: Temperature. $P$ values indicate differences between Severe and Non-severe patients. $P<$ 0.05 was considered statistically significant.

Table 5. Multivariate COX analysis of risk factors of severe cases in Guangzhou.

\begin{tabular}{lcc}
\hline & HR $(\mathbf{9 5 \%}$ CI $)$ & $P$ value \\
\hline Age $(>58.5$ years $)$ & $13.444(2.989-60.480)$ & 0.001 \\
Fever $\left(\geq 39^{\circ} \mathrm{C}\right)$ & $3.126(0.876-11.155)$ & 0.079 \\
Total bilirubin $(>7.23 \mu \mathrm{mol} / \mathrm{L})$ & $3.922(1.260-12.207)$ & 0.018 \\
\hline
\end{tabular}

Abbreviation: HR: hazard ratio.

300 people were infected [5]. At that time, the severity rate in Guangzhou was $10.4 \%$, and the mortality rate was $0.3 \%$ [5]. SARS-CoV-2 has mutated many times subsequently. Recently, the SARS-CoV-2 (B.1.167) Delta variant has raged around the world. In India, due to the widespread presence of the Delta variant, the number of COVID-19 deaths has risen from 100 to 200 deaths per day in the earlier months to about 4,000 deaths per day [1]. In the UK, in the week of June 2, about $34 \%$ of people with the Delta variant visited the emergency departments of hospitals and were admitted at hospitals overnight [2]. Influenced by SARS-CoV-2 (B.1.167), more than 100 indigenous cases were reported in Guangzhou again. It began with an elderly lady and quickly spread to the community through her family. Compared with the epidemic caused by SARSCoV-2 in Guangzhou last year, the current epidemic caused by SARS-CoV-2 (B.1.167) has the following characteristics: (1) short incubation period, 2-4 days; (2) fast propagation speed; (3) strong ability of infection; and (4) high viral load. These characteristics were the same as those reported in other countries [1, 2]. Up to June 14, of the 144 patients in our database, none died, and the severity of the Delta variant in Guangzhou was $11.4 \%$.

It was interesting to find that patients with elevated total bilirubin had a higher risk of becoming severe cases. In our study, when the total bilirubin level was greater than $7.23 \mu \mathrm{mol} / \mathrm{L}$, the risk of severe illness increased 3.922fold. Although three patients' had total bilirubin levels higher than normal, clinicians tend to ignore this indicator. Studies have shown that some COVID-19 patients have elevated total bilirubin $[6,7]$. Liang $\mathrm{W}$ et al. reported that direct bilirubin level was an independent risk factor for patients with severe COVID-19 symptoms [8]. One study showed that elevated bilirubin levels were an independent risk factor for severe cases of COVID-19 [9]. Another study of COVID-19 patients in Shenzhenand this was caused by SARS-CoV-2 - showed that total bilirubin levels were higher in severe cases [10], but that relationship was not identified in the Guangzhou study [5]. We have found this relationship in Guangzhou patients with COVID-19 caused by the Delta variant strain. Therefore, clinicians need to pay more attention to the patient's total bilirubin levels, even if the levels are not above normal.

Total bilirubin elevation was mainly seen in several cases of liver cell damage, cholestasis, and hemolysis. SARS-CoV-2 could use transmembrane serine protease 2 (TMPRSS2) as a docking and entry receptor on host cells [11]. TMPRSS2 mRNA expression was found in hepatocytes [12]. Electron microscope analysis of liver samples from two deceased COVID-19 patients with elevated liver enzymes revealed the presence of intact 
virus particles in the cytoplasm of hepatocytes [13]. The SARS-CoV-2 infection has been observed in small intestinal organoids [14, 15]. The virus replicates rapidly in the gut and could reach the liver through portal vein circulation. Hepatic Kupffer cells might trigger an inflammatory response as they attempt to clear the virus [7]. Early over-release of inflammatory cytokines in COVID-19 patients was associated with disease severity and might cause cytokine storm syndrome (CSS) [16]. CSS might cause disseminated intravascular coagulation (DIC) [17] and was associated with multiple organ failure (MOF). Microthrombotic endodermatitis and MOF-associated hepatic ischemia might cause hepatocyte injury. In addition, acetaminophen, antibiotics, corticosteroids, and immunomodulators used in treating COVID-19 patients had potential hepatotoxicity. Hypoxic hepatitis caused by hemodynamics and oxygen delivery changes could also lead to liver cell damage [7]. In postmortem assessments of COVID-19 patients, cholestasis features such as bile duct hyperplasia and inflammatory portal infiltration have been reported [18, 19]. Studies suggested that the following factors might hit bile ducts in COVID-19 patients: hypoxia due to respiratory failure or systemic inflammatory response syndrome (SIRS) leads to the spread of inflammation and fibrosis and potentially viral infection of bile duct cells [20]. Autoimmune hemolytic anemia (AIHA) with SARSCoV-2 infection may cause hemolysis [21], but no AIHA patients were included in this study. The severe patients we followed had a higher viral load than nonsevere patients. In addition, severe patients had a higher rate of antibiotics use, corticosteroids, and more obvious hypoxia, which were potential factors for liver injury or cholestasis, although these injuries were not apparent. This could well explain why the total bilirubin levels are higher in severe patients than in non-severe patients.

A wealth of evidence suggested that age itself was the most important risk factor for severe COVID-19 disease [22-24]. A study showed that age (OR, 1.057; 95\% CI, $1.018-1.098 ; P=0.004)$ was an independent risk factor for severe disease in patients with COVID-19 in Guangzhou last year [5]. Another study showed that older COVID-19 patients have more atypical symptoms, with increased comorbidities, organ injuries, secondary infection, immunodeficiency, and a higher risk of critical illness [25]. Studies from China, the United States, and Italy have shown that COVID-19 patients of different ages have different severe illness and mortality rates. Generally speaking, the older the patients were, the higher the mortality rate was [2628]. Some previous studies might explain this. First, immune-senescence and inflammation play a major role in making older patients more vulnerable to severe
COVID-19 outcomes [29, 30]. Second, Mikhail V. Blagosklonny [31] proposed that the hyperfunction theory of quasi-programmed aging explains the correlation between the age of the COVID-19 patient and the mortality rate. Because aging was driven by inappropriately high cellular functioning, cellular hyperfunctions may eventually switch to cellular exhaustion and loss of functions at late stages. Third, biological age was more relevant to COVID-19 than the chronological age, and epigenetic clocks and glycosylation clocks were biomarkers for objective estimates of biological age [30, 32]. Age-related epigenome changes have important implications for the immune system, including macrophage pattern recognition, cytokine production, and $\mathrm{T}$ cell function. Moreover, changes in glycosylation during aging might make older people more susceptible to severe COVID19 [30]. Fourth, the dysregulation of the epigenome was closely associated with chronic disease states and aging. The composition and function of immune cells can be impaired by age-related host epigenome changes [30]. Finally, the known mislocation of SIRT1 and SIRT6 throughout the genome and the decline of NAD+ during aging could be major factors causing age-dependent symptoms of COVID-19 [30]. Age was also one of the risk factors for severe patients in our study cohort. In particular, the risk of severe cases increased 13.444-fold when the patient was older than 58.5 years. Therefore, older patients need to have an early diagnosis and their systemic comorbidities treated carefully.

Fever was the most common symptom in these patients, followed by cough, sore throat, fatigue, expectoration, headache, and other symptoms. This trend was similar to that of previous studies $[5,33,34]$. It was suggested that some symptoms might be the independent risk factors for patients to develop into severe cases [9]. In our study, multivariate logistic regression analysis suggested that a temperature equal to or greater than $39^{\circ} \mathrm{C}$ was a risk factor for developing severe disease. However, in multivariate Cox regression analysis, temperature $\geq 39^{\circ} \mathrm{C}$ was excluded. According to clinical observations, some patients had no fever symptoms until 1-2 days after hospitalization; yet, the data used in these statistical analyses were registered at admission. Overall, a temperature $\geq 39^{\circ} \mathrm{C}$ remains a key concern for clinicians.

Except for age and total bilirubin, studies have shown that comorbidity, such as diabetes, and CVD, laboratory indicators, such as lymphocyte count, white blood cell count, platelet count, blood glucose, PCT, and D-dimer, and imaging findings, such as double pneumonia or severe pulmonary inflammation, were independent risk factors for severe disease and poor prognosis [35-42]. However, in our study, these relationships were not 
found. This might be related to the lack of a sufficient number of samples or the variant of the virus. Further studies are needed to clarify this issue.

There is currently no specific drug for COVID-19 patients. Some early studies reported that chloroquine, hydroxychloroquine, umifenovir (arbidol), redeliver, and traditional Chinese medicine might be effective [43-48], but recent research suggested the opposite [4951]. Vaccines were the most effective means of prevention [52], although the Delta variant is moderately resistant to vaccines, especially in people who have received only one dose [53]. Twenty-six patients in our study were infected after receiving the vaccine, but none developed severe disease.

The study has several limitations. First, the lack of laboratory data on serum cytokines, chemokines, and other factors makes it impossible to assess the levels of inflammation and cytokine storms in these patients. Second, this study lacked bile acid, hepatobiliary ultrasound, and even liver biopsy data; so, it could not further clarify the relationship between total bilirubin elevation and severe patients. Third, this is a retrospective study, and the data collected are only a preliminary assessment of the clinical characteristics and risk factors of severe cases of COVID-19. Further research is still needed.

In conclusion, our study showed that the mortality and severity of the Delta variant in Guangzhou were much lower than in the rest of the world. The risk factors for severe cases of the Delta variant in Guangzhou included older age and elevated total bilirubin, especially if the age was greater than 58.5 years or the total bilirubin level was greater than $7.23 \mu \mathrm{mol} / \mathrm{L}$. Investigating and monitoring these factors can help clinicians identify patients with poor prognoses early and initiate aggressive interventions that benefit patients and reduce the severity and mortality. Our research also provided significant experience and reference for countries around the world to fight against the Delta variant.

\section{MATERIALS AND METHODS}

\section{Study design and participants}

This study was conducted retrospectively at Guangzhou Eighth People's Hospital, the designated COVID-19 hospital in Guangzhou, China. From May 21, 2021, to June 11, 2021, 144 patients with the Delta variant were recruited. The end of the follow-up was June 14, 2021.

The study was approved by the Ethics Committee, and informed consent was obtained from all patients enrolled.

\section{Definitions}

Based on the Chinese diagnosis and treatment guideline for COVID-19 (trial version 8.0) [54], 144 patients were divided into two groups: the non-severe group (128 cases), including light and general patients, and the severe group (16 cases), including severe and critical patients. A case was defined as severe if it met any of the following: (1) shortness of breath, respiratory rate $\geq 30$ times/minute; (2) blood oxygen saturation $\leq 93 \%$ at rest; (3) oxygenation index $(\mathrm{PaO} 2 / \mathrm{FiO} 2) \leq 300 \mathrm{mmHg}$; (4) pulmonary infiltrates $>50 \%$ of the lung lesions within 24-48 hours; (5) respiratory failure, requiring mechanical ventilation; (6) shock; (7) multiple organ dysfunction, needing ICU monitoring treatment. In this study, the reference ranges of all laboratory test indicators were based on the laboratory of Guangzhou Eighth People's Hospital.

\section{Data collection}

The nursing records, clinical electronic medical records, laboratory tests, and radiological findings of the 144 patients, who were confirmed by nucleic acid testing and genetic analysis to have been infected by the Delta variant, were reviewed. In addition, the epidemiology, demographics, clinical manifestations, laboratory data, and computerized chest tomography (CT) findings were extracted for statistical analysis and research.

\section{Statistical analysis}

Continuous variables were presented as median (interquartile range), and categorical variables were presented as numbers (\%). We used a two-sample $t$-test or the Mann-Whitney $U$ test to assess the differences between severe and non-severe groups for continuous variables and used the $\chi^{2}$ test or Fisher's exact test to assess categorical variables. Univariate logistics regression analysis with a $P$-value $<0.1$ is presented in Tables 1 and 2. Then, multivariate logistic regression analysis was performed on the indicators with $P<0.05$ in univariate logistic regression analysis. The cut-off was obtained through the ROC curve. Survival time was counted from the onset of the disease until the patient's condition progressed to severe or until June 14. KaplanMeier and Cox regression analysis further investigated the risk factors of severe patients. Statistical analyses were performed using SPSS, ver. 22.0. $P<0.05$ was considered statistically significant.

\section{AUTHOR CONTRIBUTIONS}

Dr. Kaiyuan Hu developed conceptualization and wrote the manuscript under the supervision of Dr. Ming Lei. Liu Lin, Ying Liang, Xinning Shao, Zhongwei Hu, 
Hongbin Luo has participated substantially in the conceptualization and design of this work as well as the writing of the manuscript. All authors have reviewed the final version of the manuscript and have approved it for publication.

\section{ACKNOWLEDGMENTS}

We thank all physicians and patients who participated in this study.

\section{CONFLICTS OF INTEREST}

The authors declare no conflicts of interest related to this study.

\section{REFERENCES}

1. COVID-19 cases worldwide. June 24, 2021. https://www.worldometers.info/coronavirus/

2. Torjesen I. Covid-19: Delta variant is now UK's most dominant strain and spreading through schools. BMJ. 2021; 373:n1445. https://doi.org/10.1136/bmj.n1445 PMID:34088699

3. O'Dowd A. Covid-19: Cases of delta variant rise by $79 \%$, but rate of growth slows. BMJ. 2021; 373:n1596. https://doi.org/10.1136/bmj.n1596 PMID:34154997

4. Huang $C$, Wang $Y$, Li $X$, Ren L, Zhao J, Hu Y, Zhang L, Fan G, Xu J, Gu X, Cheng Z, Yu T, Xia J, et al. Clinical features of patients infected with 2019 novel coronavirus in Wuhan, China. Lancet. 2020; 395:497-506. https://doi.org/10.1016/S0140-6736(20)30183-5 PMID:31986264

5. He F, Luo $Q$, Lei $M$, Fan L, Shao X, Huang G, Zeng J, Zhao Z, Qin S, Yang Z, Yu N, Yang L, Cao J. Risk factors for severe cases of COVID-19: a retrospective cohort study. Aging (Albany NY). 2020; 12:15730-40. https://doi.org/10.18632/aging.103803 PMID: $\underline{32805730}$

6. Cha MH, Regueiro M, Sandhu DS. Gastrointestinal and hepatic manifestations of COVID-19: A comprehensive review. World J Gastroenterol. 2020; 26:2323-32.

https://doi.org/10.3748/wig.v26.i19.2323 PMID: $\underline{32476796}$

7. Bertolini A, van de Peppel IP, Bodewes FAJA, Moshage $H$, Fantin $A$, Farinati $F$, Fiorotto $R$, Jonker $J W$, Strazzabosco M, Verkade HJ, Peserico G. Abnormal Liver Function Tests in Patients With COVID-19: Relevance and Potential Pathogenesis. Hepatology. 2020; 72:1864-72. https://doi.org/10.1002/hep.31480

PMID:32702162

8. Liang $W$, Liang $\mathrm{H}, \mathrm{Ou} \mathrm{L}$, Chen B, Chen A, Li C, Li Y, Guan W, Sang L, Lu J, Xu Y, Chen G, Guo H, et al, and China Medical Treatment Expert Group for COVID-19. Development and Validation of a Clinical Risk Score to Predict the Occurrence of Critical Illness in Hospitalized Patients With COVID-19. JAMA Intern Med. 2020; 180:1081-89.

https://doi.org/10.1001/jamainternmed.2020.2033 PMID: $\underline{32396163}$

9. Izcovich A, Ragusa MA, Tortosa F, Lavena Marzio MA, Agnoletti C, Bengolea A, Ceirano A, Espinosa F, Saavedra E, Sanguine V, Tassara A, Cid C, Catalano $\mathrm{HN}$, et al. Prognostic factors for severity and mortality in patients infected with COVID-19: A systematic review. PLoS One. 2020; 15:e0241955.

https://doi.org/10.1371/journal.pone.0241955 PMID:33201896

10. Cai Q, Huang D, Yu H, Zhu Z, Xia Z, Su Y, Li Z, Zhou G, Gou J, Qu J, Sun Y, Liu Y, He Q, et al. COVID-19: Abnormal liver function tests. J Hepatol. 2020; 73:566-74. https://doi.org/10.1016/i.jhep.2020.04.006 PMID:32298767

11. Hoffmann $M$, Kleine-Weber $H$, Schroeder $S$, Krüger $N$, Herrler T, Erichsen S, Schiergens TS, Herrler G, Wu NH, Nitsche A, Müller MA, Drosten C, Pöhlmann S. SARS-CoV-2 Cell Entry Depends on ACE2 and TMPRSS2 and Is Blocked by a Clinically Proven Protease Inhibitor. Cell. 2020; 181:271-80.e8. https://doi.org/10.1016/i.cell.2020.02.052 PMID:32142651

12. Pirola CJ, Sookoian S. SARS-CoV-2 virus and liver expression of host receptors: Putative mechanisms of liver involvement in COVID-19. Liver Int. 2020; 40:2038-40.

https://doi.org/10.1111/liv.14500

PMID:32352224

13. Wang $Y$, Liu S, Liu H, Li W, Lin F, Jiang L, Li X, Xu P, Zhang L, Zhao L, Cao Y, Kang J, Yang J, et al. SARSCoV-2 infection of the liver directly contributes to hepatic impairment in patients with COVID-19. J Hepatol. 2020; 73:807-16.

https://doi.org/10.1016/j.jhep.2020.05.002 PMID: $\underline{32437830}$

14. Hikmet $F$, Méar $L$, Edvinsson $\AA$, Micke $P$, Uhlén $M$, Lindskog $C$. The protein expression profile of ACE2 in human tissues. Mol Syst Biol. 2020; 16:e9610. https://doi.org/10.15252/msb.20209610 PMID:32715618

15. Hamming I, Timens W, Bulthuis ML, Lely AT, Navis G, van Goor H. Tissue distribution of ACE2 protein, the 
functional receptor for SARS coronavirus. A first step in understanding SARS pathogenesis. J Pathol. 2004; 203:631-37.

https://doi.org/10.1002/path.1570

PMID:15141377

16. Liu J, Li S, Liu J, Liang B, Wang X, Wang H, Li W, Tong Q, Yi J, Zhao L, Xiong L, Guo C, Tian J, et al. Longitudinal characteristics of lymphocyte responses and cytokine profiles in the peripheral blood of SARSCoV-2 infected patients. EBioMedicine. 2020; 55:102763.

https://doi.org/10.1016/i.ebiom.2020.102763 PMID:32361250

17. Jose RJ, Manuel A. COVID-19 cytokine storm: the interplay between inflammation and coagulation. Lancet Respir Med. 2020; 8:e46-47. https://doi.org/10.1016/S2213-2600(20)30216-2 PMID:32353251

18. Lax SF, Skok K, Zechner P, Kessler HH, Kaufmann N, Koelblinger $\mathrm{C}$, Vander $\mathrm{K}$, Bargfrieder $\mathrm{U}$, Trauner $\mathrm{M}$. Pulmonary Arterial Thrombosis in COVID-19 With Fatal Outcome: Results From a Prospective, SingleCenter, Clinicopathologic Case Series. Ann Intern Med. 2020; 173:350-61. https://doi.org/10.7326/M20-2566 PMID:32422076

19. Lagana SM, Kudose S, luga AC, Lee MJ, Fazlollahi L, Remotti HE, Del Portillo A, De Michele S, de Gonzalez $A K$, Saqi $A$, Khairallah $P$, Chong $A M$, Park $H$, et al. Hepatic pathology in patients dying of COVID-19: a series of 40 cases including clinical, histologic, and virologic data. Mod Pathol. 2020; 33:2147-55. https://doi.org/10.1038/s41379-020-00649-x PMID: $\underline{32792598}$

20. Nardo AD, Schneeweiss-Gleixner M, Bakail M, Dixon ED, Lax SF, Trauner M. Pathophysiological mechanisms of liver injury in COVID-19. Liver Int. 2021; 41:20-32.

https://doi.org/10.1111/liv.14730

PMID: $\underline{3190346}$

21. Sahu KK, Borogovac A, Cerny J. COVID-19 related immune hemolysis and thrombocytopenia. J Med Virol. 2021; 93:1164-70.

https://doi.org/10.1002/imv.26402

PMID: $\underline{32776538}$

22. Zhou F, Yu T, Du R, Fan G, Liu Y, Liu Z, Xiang J, Wang Y, Song B, Gu X, Guan L, Wei Y, Li H, et al. Clinical course and risk factors for mortality of adult inpatients with COVID-19 in Wuhan, China: a retrospective cohort study. Lancet. 2020; 395:1054-62. https://doi.org/10.1016/S0140-6736(20)30566-3 PMID: $\underline{32171076}$
23. Wang $D$, Hu B, Hu C, Zhu F, Liu X, Zhang J, Wang B, Xiang $\mathrm{H}$, Cheng $\mathrm{Z}$, Xiong $\mathrm{Y}$, Zhao $\mathrm{Y}$, Li $\mathrm{Y}$, Wang $\mathrm{X}$, Peng Z. Clinical Characteristics of 138 Hospitalized Patients With 2019 Novel Coronavirus-Infected Pneumonia in Wuhan, China. JAMA. 2020; 323:1061-69.

https://doi.org/10.1001/jama.2020.1585 PMID:32031570

24. Salje H, Tran Kiem C, Lefrancq N, Courtejoie N, Bosetti P, Paireau J, Andronico A, Hozé N, Richet J, Dubost CL, Le Strat Y, Lessler J, Levy-Bruhl D, et al. Estimating the burden of SARS-CoV-2 in France. Science. 2020; 369:208-11.

https://doi.org/10.1126/science.abc3517 PMID: 32404476

25. Zhao $M$, Wang $M$, Zhang J, Gu J, Zhang $P, X u Y, Y e ~ J$, Wang Z, Ye D, Pan W, Shen B, He H, Liu M, et al. Comparison of clinical characteristics and outcomes of patients with coronavirus disease 2019 at different ages. Aging (Albany NY). 2020; 12:10070-86.

https://doi.org/10.18632/aging.103298 PMID:32499448

26. Wu C, Chen X, Cai $Y$, Xia J, Zhou X, Xu S, Huang H, Zhang L, Zhou X, Du C, Zhang Y, Song J, Wang S, et al. Risk Factors Associated With Acute Respiratory Distress Syndrome and Death in Patients With Coronavirus Disease 2019 Pneumonia in Wuhan, China. JAMA Intern Med. 2020; 180:934-43. https://doi.org/10.1001/jamainternmed.2020.0994 PMID:32167524

27. Onder G, Rezza G, Brusaferro S. Case-Fatality Rate and Characteristics of Patients Dying in Relation to COVID-19 in Italy. JAMA. 2020; 323:1775-76. https://doi.org/10.1001/jama.2020.4683 PMID:32203977

28. Richardson S, Hirsch JS, Narasimhan M, Crawford JM, McGinn T, Davidson KW, Barnaby DP, Becker LB, Chelico JD, Cohen SL, Cookingham J, Coppa K, Diefenbach MA, et al, and the Northwell COVID-19 Research Consortium. Presenting Characteristics, Comorbidities, and Outcomes Among 5700 Patients Hospitalized With COVID-19 in the New York City Area. JAMA. 2020; 323:2052-59.

https://doi.org/10.1001/iama.2020.6775 PMID:32320003

29. Chen $Y$, Klein SL, Garibaldi BT, Li H, Wu C, Osevala NM, Li T, Margolick JB, Pawelec G, Leng SX. Aging in COVID-19: Vulnerability, immunity and intervention. Ageing Res Rev. 2021; 65:101205. https://doi.org/10.1016/i.arr.2020.101205 PMID:33137510

30. Mueller AL, McNamara MS, Sinclair DA. Why does COVID-19 disproportionately affect older people? Aging (Albany NY). 2020; 12:9959-81. 
https://doi.org/10.18632/aging.103344 PMID:32470948

31. Blagosklonny MV. From causes of aging to death from COVID-19. Aging (Albany NY). 2020; 12:10004-21. https://doi.org/10.18632/aging.103493 PMID: 32534452

32. Lauc G, Sinclair D. Biomarkers of biological age as predictors of COVID-19 disease severity. Aging (Albany NY). 2020; 12:6490-91. https://doi.org/10.18632/aging.103052 PMID: $\underline{32268300}$

33. Li LQ, Huang $T$, Wang $Y Q$, Wang $Z P$, Liang $Y$, Huang TB, Zhang HY, Sun W, Wang Y. COVID-19 patients' clinical characteristics, discharge rate, and fatality rate of meta-analysis. J Med Virol. 2020; 92:577-83. https://doi.org/10.1002/jmv.25757 PMID:32162702

34. Rodriguez-Morales AJ, Cardona-Ospina JA, GutiérrezOcampo E, Villamizar-Peña $R$, Holguin-Rivera $Y$, Escalera-Antezana JP, Alvarado-Arnez LE, BonillaAldana DK, Franco-Paredes C, Henao-Martinez AF, Paniz-Mondolfi A, Lagos-Grisales GJ, Ramírez-Vallejo $E$, et al, and Latin American Network of Coronavirus Disease 2019-COVID-19 Research (LANCOVID-19). Clinical, laboratory and imaging features of COVID-19: A systematic review and meta-analysis. Travel Med Infect Dis. 2020; 34:101623.

https://doi.org/10.1016/i.tmaid.2020.101623 PMID:32179124

35. Shang L, Shao M, Guo Q, Shi J, Zhao Y, Xiaokereti J, Tang B. Diabetes Mellitus is Associated with Severe Infection and Mortality in Patients with COVID-19: A Systematic Review and Meta-analysis. Arch Med Res. 2020; 51:700-09. https://doi.org/10.1016/j.arcmed.2020.07.005 PMID: $\underline{32811670}$

36. Düz ME, Balcı A, Menekşe E. D-dimer levels and COVID-19 severity: Systematic Review and MetaAnalysis. Tuberk Toraks. 2020; 68:353-60.

https://doi.org/10.5578/tt.70351 PMID:33448732

37. Li $M$, Dong $Y$, Wang $H$, Guo $W$, Zhou $H$, Zhang $Z$, Tian C, Du K, Zhu R, Wang L, Zhao L, Fan H, Luo S, $\mathrm{Hu}$ D. Cardiovascular disease potentially contributes to the progression and poor prognosis of COVID-19. Nutr Metab Cardiovasc Dis. 2020; 30:1061-67.

https://doi.org/10.1016/j.numecd.2020.04.013 PMID: 32456948

38. Shang $Y$, Liu T, Wei $Y$, Li J, Shao L, Liu M, Zhang $Y$, Zhao Z, Xu H, Peng Z, Zhou F, Wang X. Scoring systems for predicting mortality for severe patients with COVID-19. EClinicalMedicine. 2020; 24:100426. https://doi.org/10.1016/i.eclinm.2020.100426 PMID:32766541

39. Liu J, Zhang S, Wu Z, Shang Y, Dong X, Li G, Zhang L, Chen Y, Ye X, Du H, Liu Y, Wang T, Huang S, et al. Clinical outcomes of COVID-19 in Wuhan, China: a large cohort study. Ann Intensive Care. 2020; 10:99. https://doi.org/10.1186/s13613-020-00706-3 PMID: $\underline{32737627}$

40. Liu SP, Zhang Q, Wang W, Zhang $M$, Liu C, Xiao X, Liu $Z$, Hu WM, Jin P. Hyperglycemia is a strong predictor of poor prognosis in COVID-19. Diabetes Res Clin Pract. 2020; 167:108338.

https://doi.org/10.1016/j.diabres.2020.108338 PMID:32712122

41. Maquet J, Lafaurie M, Sommet A, Moulis G. Thrombocytopenia is independently associated with poor outcome in patients hospitalized for COVID-19. Br J Haematol. 2020; 190:e276-79.

https://doi.org/10.1111/bjh.16950

PMID: $\underline{32557535}$

42. Chon Y, Kim JY, Suh YJ, Lee JY, Park JS, Moon SM, Lee MS, Yi J. Adverse Initial CT Findings Associated with Poor Prognosis of Coronavirus Disease. J Korean Med Sci. 2020; 35:e316.

https://doi.org/10.3346/jkms.2020.35.e316

PMID: $\underline{32864912}$

43. Arshad S, Kilgore P, Chaudhry ZS, Jacobsen G, Wang DD, Huitsing K, Brar I, Alangaden GJ, Ramesh MS, McKinnon JE, O'Neill W, Zervos M, and Henry Ford COVID-19 Task Force. Treatment with hydroxychloroquine, azithromycin, and combination in patients hospitalized with COVID-19. Int J Infect Dis. 2020; 97:396-403.

https://doi.org/10.1016/j.ijid.2020.06.099 PMID:32623082

44. Gao J, Tian Z, Yang X. Breakthrough: Chloroquine phosphate has shown apparent efficacy in treatment of COVID-19 associated pneumonia in clinical studies. Biosci Trends. 2020; 14:72-73.

https://doi.org/10.5582/bst.2020.01047 PMID: 32074550

45. Wang $M$, Cao R, Zhang L, Yang X, Liu J, Xu M, Shi Z, Hu Z, Zhong W, Xiao G. Remdesivir and chloroquine effectively inhibit the recently emerged novel coronavirus (2019-nCoV) in vitro. Cell Res. 2020; 30:269-71.

https://doi.org/10.1038/s41422-020-0282-0 PMID:32020029

46. Grein J, Ohmagari N, Shin D, Diaz G, Asperges E, Castagna A, Feldt T, Green G, Green ML, Lescure FX, Nicastri E, Oda R, Yo K, et al. Compassionate Use of Remdesivir for Patients with Severe Covid-19. N Engl J Med. 2020; 382:2327-36. 
https://doi.org/10.1056/NEJMoa2007016

PMID:32275812

47. Spinner CD, Gottlieb RL, Criner GJ, Arribas López JR, Cattelan AM, Soriano Viladomiu A, Ogbuagu O, Malhotra P, Mullane KM, Castagna A, Chai LYA, Roestenberg M, Tsang OTY, et al, and GS-US-5405774 Investigators. Effect of Remdesivir vs Standard Care on Clinical Status at 11 Days in Patients With Moderate COVID-19: A Randomized Clinical Trial. JAMA. 2020; 324:1048-57.

https://doi.org/10.1001/jama.2020.16349

PMID: $\underline{32821939}$

48. Zhao Z, Li Y, Zhou L, Zhou X, Xie B, Zhang W, Sun J. Prevention and treatment of COVID-19 using Traditional Chinese Medicine: A review. Phytomedicine. 2021; 85:153308.

https://doi.org/10.1016/i.phymed.2020.153308

PMID:32843234

49. Hernandez AV, Roman YM, Pasupuleti V, Barboza JJ, White CM. Hydroxychloroquine or Chloroquine for Treatment or Prophylaxis of COVID-19: A Living Systematic Review. Ann Intern Med. 2020; 173:287-96. https://doi.org/10.7326/M20-2496 PMID:32459529

50. Huang $D, Y u H$, Wang $T$, Yang $H$, Yao $R$, Liang $Z$. Efficacy and safety of umifenovir for coronavirus disease 2019 (COVID-19): A systematic review and meta-analysis. J Med Virol. 2021; 93:481-90. https://doi.org/10.1002/jmv.26256

PMID:32617989

51. Beigel JH, Tomashek KM, Dodd LE. Remdesivir for the Treatment of Covid-19 - Preliminary Report. Reply. N Engl J Med. 2020; 383:994.

https://doi.org/10.1056/NEJMc2022236

PMID: $\underline{32649078}$

52. Chen W. Promise and challenges in the development of COVID-19 vaccines. Hum Vaccin Immunother. 2020; 16:2604-08.

https://doi.org/10.1080/21645515.2020.1787067 PMID:32703069

53. Callaway E. Delta coronavirus variant: scientists brace for impact. Nature. 2021; 595:17-18.

https://doi.org/10.1038/d41586-021-01696-3 PMID:34158664

54. National Health Commission of the People's Republic of China. Chinese diagnosis and treatment guideline for COVID-19 (trial version 8.0). April 15, 2021. http://www.nhc.gov.cn/xcs/zhengcwj/202104/7de0b 3837c8b4606a0594aeb0105232b.shtml 